\title{
Endocrine activities and adipogenic effects of bisphenol AF and its main metabolite
}

\section{Skledar, Darja Gramec}

2019-01

Skledar , D G , Carino , A , Trontelj , J , Troberg , J , Distrutti , E , Marchiano , S , Tornasic , T , Zega , A , Finel , M , Fiorucci , S \& Maisic , L P 2019, ' Endocrine activities and adipogenic effects of bisphenol AF and its main metabolite ' , Chemosphere, vol. 215 , pp. 870-880 . https://doi.org/10.1016/j.chemosphere.2018.10.129

http://hdl.handle.net/10138/325049

https://doi.org/10.1016/j.chemosphere.2018.10.129

cc_by_nc_nd

acceptedVersion

Downloaded from Helda, University of Helsinki institutional repository.

This is an electronic reprint of the original article.

This reprint may differ from the original in pagination and typographic detail.

Please cite the original version. 


\section{Endocrine Activities and Adipogenic Effects of Bisphenol AF and Its Main Metabolite} (

(1)

Darja Gramec Skledara, Adriana Carino ${ }^{\mathrm{b}}$, Jurij Trontelja, Johanna Trobergc, Eleonora Distrutti $^{b}$, Silvia Marchianò ${ }^{b}$, Tihomir Tomašičca, Anamarija Zega ${ }^{a}$, Moshe Finelc, Stefano Fioruccib, Lucija Peterlin Mašiča*

aFaculty of Pharmacy, University of Ljubljana, Aškerčeva 7, 1000 Ljubljana, Slovenia bDipartimento di Medicina Clinica e Sperimentale, Nuova Facultà di Medicina e Chirurgia, University of Perugia, S. Andrea delle Fratte, 06132 Perugia, Italy

cDivision of Pharmaceutical Chemistry, Faculty of Pharmacy, University of Helsinki, Helsinki, Finland

\section{*Corresponding author: Lucija Peterlin Mašič}

Faculty of Pharmacy

University of Ljubljana

Aškerčeva 7

1000 Ljubljana, Slovenia

Tel: +386-1-4769635

E-mail: lucija.peterlin@ffa.uni-lj.si 


\section{Abstract}

Bisphenol AF (BPAF) is a fluorinated analog of bisphenol A (BPA), and it is a more potent estrogen receptor (ER) agonist. BPAF is mainly metabolized to BPAF-glucuronide (BPAFG), which has been reported to lack ER agonist activity and is believed to be biologically inactive. The main goal of the current study was to examine the influence of the metabolism of BPAF via glucuronidation on its ER activity and adipogenesis. Also, as metabolites can have different biological activities, the effects of BPAF-G on other nuclear receptors were evaluated. First, in-vitro BPAF glucuronidation was investigated using recombinant human enzymes. Specific reporter-gene assays were used to determine BPAF and BPAF-G effects on estrogen, androgen, glucocorticoid, and thyroid receptor pathways, and on PXR, FXR, and PPAR $\gamma$ pathways. Their effects on lipid accumulation and differentiation were determined in murine 3T3L1 preadipocytes using Nile Red, with mRNA expression analysis of the adipogenic markers adiponectin, Fabp4, Cebpo, and PPAR $\gamma$. BPAF showed strong agonistic activity for $\mathrm{hER} \alpha$ and moderate antagonistic activities for androgen and thyroid receptors, and for PXR. BPAF-G was antagonistic for PXR and PPAR $\gamma$. BPAF $(0.1 \mu \mathrm{M})$ and BPAF-G $(1.0 \mu \mathrm{M})$ induced lipid accumulation and increased expression of key adipogenic markers in murine preadipocytes. BPAF-G is therefore not an inactive metabolite of BPAF. Further toxicological and epidemiological investigations of BPAF effects on human health are warranted, to provide better understanding of the metabolic end-elimination of BPAF.

Keywords: Bisphenol AF, bisphenol AF glucuronide, glucuronidation, endocrine activities, lipid accumulation 


\section{Abbreviations}

51

52

53

54

55

60

BPA, bisphenol A; BPAF, bisphenol AF; BPAF-G, bisphenol AF glucuronide; BPS, bisphenol S; CDCA, chenodeoxycholic acid; DIM, differentiation mix (DMEM, 10\% fetal calf serum, $517 \mu \mathrm{M}$ 3-isobutyl-1-methylxanthine, $1 \mu \mathrm{M}$ dexamethasone, $172 \mathrm{nM}$ insulin); DMEM, Dulbecco's modified Eagle's medium; E2, 17- $\beta$-estradiol; ER, estrogen receptor; FXR, farnesoid receptor; HIM, human intestine microsomes; HLM, human liver microsomes; NADPH, $\beta$-nicotinamide adenine dinucleotide phosphate; PBS, phosphate-buffered saline; PPAR, peroxisome proliferator-activated receptor; PXR, pregnane X receptor; T3, triiodothyronine; UDPGA, uridine 5'diphosphoglucuronic acid; UGT, 5'-diphosphoglucuronosyltransferase 


\section{Introduction}

Bisphenol AF (BPAF; 1,1,1,3,3,3-hexafluoro-2,2-bis (4-hydroxyphenyl)propane) is a fluorinated analog of the endocrine-disrupting bisphenol A (BPA; Fig. 1). BPAF is extensively used in the production of fluoroelastomers and fluoropolymers, and it has already been detected in various environmental matrices near manufacturing plants, including rivers, soil, and sediment (Song et al., 2012). BPAF has also been detected in sewage sludge (up to $72.2 \mathrm{ng} / \mathrm{g}$ dry weight) (Yu et al., 2015), indoor dust (Liao et al., 2012), and honey samples (up to $53.5 \mathrm{ng} / \mathrm{mL}$ ) (Cesen et al., 2016). On the other hand, BPAF was not detected in canned and noncanned beverages (Regueiro and Wenzl, 2015a), nor in ready-made meals (Regueiro and Wenzl, 2015b). Currently, the estimated dietary intake of BPAF is $0.49 \mathrm{ng} / \mathrm{kg}$ body weight/day for men and $0.50 \mathrm{ng} / \mathrm{kg}$ body weight/day for women (Liao and Kannan, 2013). However, due to the extensive replacement of BPA by its analogs, it is likely that the exposure to BPAF and to the other BPA substitutes will rise in the coming years.

In previous in-vitro studies, BPAF showed higher estrogen receptor (ER) agonistic activity than BPA (Table 1). This higher activity was defined using luciferase reporter assays in several cell lines, including MCF7 (Kitamura et al., 2005), MVLN (Song et al., 2014), and CV-1 monkey kidney (Teng et al., 2013) cells. Similarly, ER agonistic activities for BPAF were shown in yeast cells (Fic et al., 2014; Ruan et al., 2015; Lei et al., 2016), and in in-vivo vitellogenin assays (Song et al., 2014).

Bisphenol AF is mainly metabolized to its corresponding glucuronide (BPAF-G; Fig. 1) and sulfate conjugates, both in vivo (Li et al., 2013; Feng et al., 2016) and in vitro (Waidyanatha et al., 2015). Formation of BPAF-G from BPAF in vivo is rapid and efficient. Indeed, for rats treated with $20 \mathrm{mg} / \mathrm{kg} B P A F$, the BPAF-G peak was detected in plasma 30 
min after oral administration (Li et al., 2013). Following oral administration in rats, BPAF$\mathrm{G}$ is mainly excreted in bile and is further deconjugated in the intestine to the parent BPAF (Waidyanatha et al., 2015). Li et al. (2013) also tested some uridine 5'-diphosphoglucuronosyltransferases (UGTs), and reported that the main UGT involved in BPAF glucuronidation is UGT2B7, followed by UGT1A3, UGT2B15, UGT1A9, UGT2B17, UGT1A1, UGT1A8, and UGT2A4 (Li et al., 2013). As expected, the bisphenol glucuronides evaluated lacked ER agonistic activity; namely, BPA-glucuronide (BPA-G) (Matthews et al., 2001), bisphenol S (BPS)-glucuronide (BPS-G) (Skledar et al., 2016), and BPAF-G (Li et al., 2013). BPA-G has been considered to be an inactive BPA metabolite, although it cannot be regarded as completely inactive as it can induce adipocyte differentiation (Boucher et al., 2015). BPA and BPS have metabolic effects and act as environmental obesogens, as they can induce lipid accumulation and increase expression of adipogenic markers in murine preadipocytes through peroxisome proliferator-activated receptor (PPAR) $\gamma$ activation (Ahmed and Atlas, 2016). However, no such studies have been performed for BPAF, or its main metabolite.

In addition to its estrogenic activity, BPAF has in-vitro androgen receptor antagonistic activity at low micromolar concentrations (Table 1), as demonstrated in yeast (Fic et al., 2014), and in NIH3T3 (Kitamura et al., 2005), CV1 (Teng et al., 2013) and MDA-kb2 (Kolšek et al., 2015) cells. BPAF is a relatively weak pregnane X receptor (PXR) activator compared to BPA (Sui et al., 2012). The thyroid hormone activities of bisphenols were evaluated by measuring growth-hormone production in GH3 cells, an assay in which BPAF was inactive (Kitamura et al., 2005). In contrast, using yeast two-hybrid assays, BPAF was shown to have thyroid hormone receptor agonistic activity that was greater than that of BPA (Table 1) (Lei et al., 2016). Additionally, disruption of thyroid hormone activity was shown in zebrafish larvae, which resulted in a robust decrease in thyroid 
111 hormone levels and disruption of gene transcription in the hypothalamic-pituitarythyroid axis (Tang et al., 2015).

Bisphenol AF also has the highest DNA-damaging potential among several bisphenols in human peripheral blood mononuclear cells (Mokra et al., 2016). This was shown using alkaline and neutral versions of the comet assay, where BPA and BPAF induced single-strand breaks in DNA even at $10 \mathrm{ng} / \mathrm{mL}$. BPAF had higher spermatogonial toxicity in comparison to BPA and BPS, which included dose-dependent and timedependent alterations in nuclear morphology, the cell cycle, and DNA damage responses, and perturbation of the cytoskeleton (Liang et al., 2017). In an in-vivo study on aquatic organisms, BPAF had greater toxicity toward Daphnia magna, Danio rerio, and Desmodesmus subspicatus compared to BPA and BPF (Tisler et al., 2016).

We have previously used physiologically based pharmacokinetic models models to compare internal exposure to BPA, BPS, BPF, and BPAF after peroral and dermal exposure in different age groups (Karrer et al., 2018). BPAF glucuronidation in microsome preparations from human liver (HLMs) and intestine (HIMs) followed substrate inhibition kinetics, which reached maximum inhibition well below $100 \mu \mathrm{M}$. At higher substrate concentrations, the BPAF glucuronidation rate was slower than that of BPA, BPS, and BPF. However, under realistic exposure conditions, the BPAF glucuronidation rate would be expected to be greater than that of other BPA analogs (Karrer et al., 2018). As glucuronidation was reported as the main metabolic pathway for BPAF, in the present study we performed a detailed in-vitro analysis of BPAF glucuronidation using 17 recombinant human UGTs, which included UGTs that are not commercially available, with the addition of HLMs and HIMs. As BPAF-G was not commercially available, we performed enzyme-assisted synthesis of BPAF-G using the human recombinant enzyme UGT2A1 (see Data in Brief). To date, BPAF-G has been tested only in terms of its estrogenic activity; 
however, in the present study, we compared the activities of BPA, BPAF, and BPAF-G on ER, androgen receptor, glucocorticoid receptor, and thyroid receptor pathways, and on PXR, PPAR $\gamma$, and farnesoid receptor (FXR) pathways, using in-vitro reporter gene assays. In addition, the effects of BPAF and BPAF-G on lipid accumulation and differentiation of the murine 3T3L1 preadipocyte cell line were examined. The results of the present study show that BPAF-G is not an inactive metabolite, as it has antagonistic activities toward nuclear receptor pathways, induces lipid accumulation in murine preadipocytes, and increases expression of several key adipogenic markers at the mRNA level.

\section{Materials and methods}

\subsection{Materials}

Bisphenol AF (97\%; CAS 1478-61-1), BPA (99\%; CAS 80-05-7), $\beta$-nicotinamide adenine dinucleotide phosphate (NADPH, reduced tetra(cyclohexylammonium) salt; CAS 10092971-3), L-glutathione ( $\geq 98 \%$; CAS 70-18-8), uridine 5'diphosphoglucuronic acid (UDPGA; ammonium salt; 98\%-100\%, CAS 43195-60-4), alamethicin (CAS 27061-78-5), sodium phosphate monobasic, anhydrous (>98\%; CAS 7558-80-7), magnesium chloride ( $\geq 98 \%$; CAS 7786-30-3), insulin (CAS I9278), isobutylmethylxanthine (CAS I5879), dimethyl sulfoxide and dexamethasone were all from Sigma-Aldrich (St. Louis, MO, USA). BPAF-G was biosynthesized in the Faculty of Pharmacy, University of Ljubljana (Slovenia), as described in the Data in Brief. Pooled human liver microsomes (HLMs; $20 \mathrm{mg} / \mathrm{mL}$ ), pooled human intestinal microsomes (HIMs; $20 \mathrm{mg} / \mathrm{mL}$ ) and recombinant human UGT2B15 'supersomes' were from BD Biosciences (Franklin Lakes, NJ, USA). Recombinant human UGTs 1A1, 1A3-1A10, 2A1-2A3, 2B4, 2B7, 2B17, and 2B28 were produced in the Division of Pharmaceutical Chemistry, University of Helsinki (Finland). Methanol and acetonitrile 
were liquid chromatography-mass spectrometry grade, and were from Sigma-Aldrich (St. Louis, MO, USA). 17- $\beta$-Estradiol (E2, $\geq 98 \%$, CAS 50-28-2), dihydrotestosterone ( $\geq 98 \%$, CAS 521-18-6), hydrocortisone ( $\geq 98 \%$, CAS $50-23-7$ ), flutamide ( $\geq 99 \%$, CAS 13311-847), mifepristone ( $\geq 98 \%$, CAS 84371-65-3), 3,3',5-triiodo-L-thyronine (T3, $\geq 95 \%$, CAS 6893-02-3), ethanolamine ( $\geq 99 \%$, CAS 141-43-5), sodium selenite ( $\geq 98 \%$, CAS 10102-188), human apotransferin ( $\geq 98 \%$, CAS 11096-37-0), bovine serum albumin ( $\geq 98 \%$, CAS 9048-46-8), 17- $\alpha$-estradiol ( $\geq 98 \%$, CAS 57-91-0), corticosterone ( $\geq 98.5 \%$, CAS 50-22-6), tamoxifen ( $\geq 99 \%$, CAS 10540-29-1) and kanamycin solution from Streptomyces kanamyceticus (10 mg/mL, CAS 25389-94-0) were from Sigma-Aldrich, Germany. HepG2 cells were from American Type Culture Collection (ATCC HB-8065; LGC Standards S.r.l., Italy). 3T3-L1 cells were from the Health Protective Agency culture collection, and were supplied by Sigma Aldrich (St. Louis, MO, USA). FuGENE (R) HD Transfection Reagent (E2311) and the Dual-Luciferase(R) Reporter assay system (E1980) were from Promega Italia S.r.l. (Milan, Italy). TRIzol reagent (REF 15596026), DNaseI (REF 18068-015), and SuperScriptII (REF 18064-014) were from Invitrogen. SYBR Select Master Mix (REF 4472908) was from Applied Biosystems. Alexafluor488-conjugated phalloidin and Nile Red solution were from ThermoFisher Scientific.

\subsection{Glucuronidation assay}

Bisphenol AF glucuronidation activity was tested with both recombinant human UGTs and pooled HLMs and HIMs. Stock solutions of BPAF were prepared in methanol. The reaction mixture (final volume, $100 \mu \mathrm{L}$ ) contained $50 \mathrm{mM}$ phosphate buffer, pH 7.4, 10 $\mathrm{mM} \mathrm{MgCl} 2,20 \mu \mathrm{M}$ or $50 \mu \mathrm{M} \mathrm{BPAF}$, and the enzyme source (final concentration, $0.2 \mathrm{mg}$ protein $/ \mathrm{mL}$ ). To avoid solubility problems, $2 \%$ dimethylsulfoxide was also added to the reaction mixture. In assays with microsomes, the reaction mixture also contained 
alamethicin (final concentration, 5\% of total microsomal protein concentration). These reaction mixtures were incubated on ice for $30 \mathrm{~min}$, and then at $37{ }^{\circ} \mathrm{C}$ for $5 \mathrm{~min}$. The reactions were started by addition of UDPGA (final concentration, $5 \mathrm{mM}$ ), and following a 60-min incubation at $37{ }^{\circ} \mathrm{C}, 10 \mu \mathrm{L} 70 \%$ perchloric acid was added, to terminate the reaction. The samples were then transferred to ice for $15 \mathrm{~min}$, centrifuged at $16000 \times g$ for $10 \mathrm{~min}$, and the supernatants were subjected to HPLC analysis. The assays were performed in triplicate. Control samples (i.e., without UDPGA, without substrate) were included in each set of assays.

The HPLC-UV analyses were performed using an Agilent 1100 series HPLC system (Agilent Technologies, Palo Alto, CA, USA) equipped with a Poroshell 120 EC-C18 column (4.6 $\times 100 \mathrm{~mm}, 2.7 \mu \mathrm{m}$; Agilent Technologies) that was maintained at $40{ }^{\circ} \mathrm{C}$, with a flow rate of $1 \mathrm{~mL} / \mathrm{min}$. The BPAF and BPAF-G separation was achieved using the mobile phases of $0.1 \%$ formic acid (A) and acetonitrile (B), as follows: $0 \rightarrow 3 \mathrm{~min}, 35 \% \mathrm{~B} ; 3 \rightarrow 6 \mathrm{~min}$, $35 \% \rightarrow 65 \%$ B; $6 \rightarrow 8 \mathrm{~min}, 65 \% \mathrm{~B} ; 8 \rightarrow 8.1 \mathrm{~min}, 65 \% \rightarrow 35 \% \mathrm{~B} ; 8.1 \rightarrow 10 \mathrm{~min}, 35 \%$ B. Detection was performed at $231 \mathrm{~nm}$. The chromatograms were analyzed using the Agilent ChemStation software (rev. B.01.01), in Windows XP Professional.

\subsection{Reporter gene assays}

The detailed descriptions of the reporter gene assays for determination of activities on several nuclear receptors are given in Supplementary Material S2.

\subsection{T3-L1 cell differentiation, RNA isolation and qRT-PCR}

The 3T3-L1 cells were cultured in Dulbecco's modified Eagle's medium (DMEM; Euroclone), supplemented with 10\% fetal bovine serum (Euroclone), 1\% L-glutamine (Euroclone), $100 \mathrm{U} / \mathrm{mL}$ penicillin (Sigma), and $100 \mu \mathrm{g} / \mathrm{mL}$ streptomycin (Sigma), at $37^{\circ} \mathrm{C}$. 
211 Preadipocytes of 3T3-L1 cells were plated at $1.7 \times 10^{6}$ cells in T75 flasks, and grown to

212 confluence. Two days after reaching confluence (day 0), the cells were stimulated with differentiation mix (DIM), either alone (DMEM, 10\% fetal calf serum, $517 \mu \mathrm{M}$ 3-isobutyl1-methylxanthine, $1 \mu \mathrm{M}$ dexamethasone, $172 \mathrm{nM}$ insulin), or in combination with increasing concentrations of the bisphenols (final concentrations, $0.1,1.0,10 \mu \mathrm{M}$ ). On day 2, the DIM was replaced by insulin medium (DMEM, 10\% fetal bovine serum, $172 \mathrm{nM}$ insulin) alone or with the bisphenols. The medium was subsequently replaced every 2 days until day 8.

To evaluate the activation of the lipidogenic and differentiation marker genes, total RNA was isolated using the TRIzol reagent (Invitrogen), according to the manufacturer specifications. One microgram RNA of genomic DNA was purified by DNaseI treatment (Invitrogen), and random reverse-transcribed with Superscript II (Invitrogen; reaction volume, $20 \mu \mathrm{L}$ ). Twenty-five nanogram template was added to a PCR mixture (final volume, $20 \mu \mathrm{L}$ ) containing $0.2 \mu \mathrm{M}$ each primer and $10 \mu \mathrm{L} 2 \times$ SYBR Select Universal ready mix (Invitrogen). All of the reactions were performed in triplicate, and the thermal cycling conditions were: $2 \mathrm{~min}$ at $95^{\circ} \mathrm{C}$, followed by 40 cycles of $95^{\circ} \mathrm{C}$ for $10 \mathrm{~s}, 60{ }^{\circ} \mathrm{C}$ for $45 \mathrm{~s}$ (StepOnePlus instrument; Applied Biosystems). The relative mRNA expression was calculated and is expressed as 2-(DDCt). The following forward and reverse primer sequences were used: mouse glyceraldehyde-3-phosphate dehydrogenase (GAPDH): ctgagtatgtcgtggagtctac and gttggtggtgcaggatgcattg; mouse adiponectin: gacaggagatcttggaatgaca and gaatgggtacattgggaacagt; mouse Fabp4: aaacaccgagatttccttcaaa and tcacgcctttcataacacattc; mouse CEBP $\alpha$ : gacatcagcgcctacatcga and tcggctgtgctggaagag; mouse PPAR $\gamma$ : gccagtttcgatccgtagaa and aatccttggccetctgagat.

\subsection{Nile Red staining}


Differentiated 3T3L1 cells were cultured on $22 \times 22 \mathrm{~mm}$ glass coverslips, treated, and then washed three times with phosphate-buffered saline (PBS), and fixed for 15 min with 4\% paraformaldehyde. The cells were then rinsed three times with PBS, and stained with Alexafluor488-conjugated phalloidin (1:100 dilution; ThermoFisher Scientific) and Nile Red solution (1:500, diluted from $5 \mathrm{mg} / \mathrm{mL}$; ThermoFisher Scientific) in PBS. The cells were then washed three times with PBS, and mounted on cover slips using SlowFade Gold mounting medium with DAPI. In-silico fluorescence quantification was carried out (AxioVision software; Zeiss Microscopy) through the co-localization scatter plots dedicated tool. The fluorescence-intensity threshold for the red fluorescent signal (i.e., Nile Red emission) was set to 1000 , which is enough to well separate digital noise, cell autofluorescence background, and low-intensity signals (i.e., membranes) from the highintensity signals that are typical of lipid droplets and lipid accumulations. Pixels above the given threshold were then normalized to the control group of cells (set as 100), and plotted using Graph-Pad Prism 7.

\subsection{Data analysis}

The GraphPad Prism 5.04 software for Windows (GraphPad Software Inc., San Diego, CA, USA) and Microsoft Excel were used to analyze the data obtained in the in-vitro assays for the different nuclear receptors. The data collected from three independent experiments were fitted using the GraphPad Prism software, and the representative values were calculated (i.e., $\mathrm{EC}_{50}, \mathrm{IC}_{50}$ ).

The bisphenols were considered as agonistic for the relevant receptor pathway if their maximal response level was at least $10 \%$ of the maximum response induced by the positive controls, as $1 \mathrm{nM}$ E2 for estrogenic activity, $0.25 \mathrm{nM}$ T3 for thyroid activity, 0.5 $\mathrm{nM}$ dihydrotestosterone for androgenic activity, $500 \mathrm{nM}$ hydrocortisone for 
glucocorticoid activity, $10 \mu \mathrm{M}$ rifaximin for PXR activity, $10 \mu \mathrm{M}$ chenodeoxycholic acid

262

263

264

265

266 (CDCA) for FXR activity, and $100 \mathrm{nM}$ rosiglitazon for PPAR $\gamma$ activity. Alternatively, the bisphenols were considered as antagonistic for these receptor pathways if they showed at least 30\% inhibition of the relevant agonist activity. The endocrine-disrupting activities toward these receptors were analyzed using two-sample student's t-tests, where ${ }^{*} p<0.05$, ${ }^{* *} p<0.01$ and ${ }^{* * *} p<0.001$ were considered statistically significant.

Computation of $\mathrm{EC}_{50}$ values and the statistics was performed using the Graph Pad Prism 5.04 software. Data are expressed as means \pm standard error, while two-group comparisons used t-test analysis of means with post-hoc Mann-Whitney tests. Differences were considered statistically significant for $\mathrm{p}<0.05$.

\section{Results}

\subsection{BPAF glucuronidation by human liver and intestine microsomes, and by} recombinant human UGTs

The glucuronidation of BPAF was tested using 17 recombinant human UGTs of subfamilies 1A, 2A, and 2B: UGTs 1A1, 1A3-1A10, 2A1-2A3, 2B4, 2B7, 2B15, 2B17, and 2B28. Two substrate concentrations were used: $20 \mu \mathrm{M}$ and $50 \mu \mathrm{M}$ BPAF (Fig. 2A, B). The highest BPAF glucuronidation rates were seen for the extrahepatic UGTs, particularly intestinal UGT1A10 and two UGTs that are located mainly in the airways and nasal epithelium, UGT2A1 and UGT2A2 (which are not expressed in liver or intestine). A number of the hepatic UGTs catalyzed BPAF glucuronidation: UGT2B7, UGT2B17, UGT1A9, and UGT1A3, and also UGT1A1, to a lesser degree.

Bisphenol AF glucuronidation rates for HLMs and HIMs were also evaluated to determine the predominant glucuronidation site of this BPA analog. The BPAF 
glucuronidation rates were about 4-fold higher with HLMs than HIMs (Fig. 2C). The most likely reason for the higher activity in HLMs is the 20-fold higher expression level of UGT2B7 in HLMs compared to HIMs, along with the large and meaningful amounts of UGT1A9 and UGT1A3 in HLMs, which are either not expressed or are barely expressed in HIMs, at the protein level (Sato et al., 2014).

Bisphenol AF glucuronidation kinetics analyses were performed for the UGTs that showed significant activities: UGTs 1A3, 1A10, 2A1, 2B7, and 2B17. Most of these BPAF glucuronidation kinetics followed the substrate inhibition model (i.e., UGTs 1A3, 1A10, 2B7, 2B17), even if they showed different sensitivities for the substrate. The kinetics of UGT 2A1 were better described by the Michaelis-Menten model (see Data in Brief), and this extra-hepatic and extra-intestinal UGT showed the highest $V_{\max }(3.30 \mathrm{nmol} / \mathrm{min} / \mathrm{mg}$ protein), followed closely by UGT $1 \mathrm{~A} 10\left(3.03 \mathrm{nmol} / \mathrm{min} / \mathrm{mg}\right.$ protein). The $\mathrm{V}_{\max }$ for the largely hepatic UGTs were about one tenth of these (see Data in Brief). On the other hand, the mainly hepatic UGT 2B7 and UGT 2B17 showed high affinities, with $\mathrm{K}_{\mathrm{m}}$ of $0.9 \mu \mathrm{M}$ and $1.12 \mu \mathrm{M}$, respectively.

\subsection{BPA, BPAF, and BPAF-G effects on nuclear receptors}

Estrogenic activity was determined using a hER $\alpha$-mediated transactivation assay in Hela9903 cells, according to the recently available new OECD guideline 455 (Fig. 3). First, the system responsiveness was confirmed by tests with reference substances. Agonism toward hER $\alpha$ was tested using E2 as a strong estrogen, 17- $\alpha$-estradiol as a weak estrogen, and corticosterone as a negative control. The data obtained were within the specified ranges reported previously, with $\mathrm{EC}_{50}$ of $1.91 \times 10^{-5} \mu \mathrm{M}$ for $\mathrm{E} 2$, and $2.24 \times 10^{-3} \mu \mathrm{M}$ for 17 $\alpha$-estradiol, and with corticosterone showing no activity. BPA and BPAF showed concentration-dependent agonistic activities toward $\mathrm{hER} \alpha$, while BPAF-G showed no 
activity toward $\mathrm{hER} \alpha$, as expected. The estrogenic activity of BPAF was 7.5-fold that of BPA, with $\mathrm{EC}_{50}$ of $0.15 \mu \mathrm{M}$ and $1.12 \mu \mathrm{M}$, respectively (Fig. 3A, Table 2). In contrast to these agonistic activities, none of these tested bisphenols showed antagonistic activities towards the hER $\alpha$ pathways (Fig. 3B). The reference substance that was used in the antagonistic assays was tamoxifen, which showed an $\mathrm{IC}_{50}$ of $0.58 \mu \mathrm{M}$ (Table 2).

Thyroid endocrine activity was determined with a reporter gene assay in GH3.TRE-Luc cells, where T3 was used as the positive control, with an $\mathrm{EC}_{50}$ of $0.12 \mathrm{nM}$. None of these tested bisphenols showed agonistic thyroid activities (Fig. 3C). In contrast, BPAF was over 10 -fold more potent in its thyroid antagonistic activity than BPA, with $\mathrm{IC}_{50}$ of 7.6 $\mu \mathrm{M}$ and $88.2 \mu \mathrm{M}$, respectively (Fig. 3D). BPAF-G showed no activity toward the thyroid receptors in these GH3.TRE-Luc cells (Fig. 3C, D).

Androgenic and glucocorticoid activities were determined with reporter gene assays using MDA-kb2 cells, which stably express both androgen and glucocorticoid receptors. None of the tested bisphenols showed any agonistic activities in this system (Fig. 3E, G). The controls used in these assays were dihydrotestosterone (androgen receptor agonist) and hydrocortisone (glucocorticoid receptor agonist), with $\mathrm{EC}_{50}$ of 1.2 $\times 10^{-3} \mu \mathrm{M}$ and $0.01 \mu \mathrm{M}$ for their respective receptor systems. BPAF-G also showed no antagonistic activities on these MDA-kb2 cells. BPAF and BPA showed antagonistic androgenic activities in the range of the control flutamide activity, with $\mathrm{IC}_{50}$ of $2.9 \mu \mathrm{M}$ for BPAF, $5.5 \mu \mathrm{M}$ for BPA, and $2.2 \mu \mathrm{M}$ for flutamide (Fig. 3F). BPA and BPAF also showed antagonistic glucocorticoid activities, although only at the higher concentrations tested, and due to their cytotoxicities at $>25 \mu \mathrm{M}$ for BPAF and $>50 \mu \mathrm{M}$ for BPA, their doseresponse curves and $\mathrm{IC}_{50}$ could not be determined here (Fig. $3 \mathrm{H}$ ).

Bisphenol A, BPAF and BPAF-G were also evaluated for their hPXR agonistic (Fig. 4A) and antagonistic (Fig. 4B) activities, using a transactivation assay in HepG2 cells. BPA 
showed the most potent PXR agonistic activity, with an $\mathrm{EC}_{50}$ of $650 \mathrm{nM}$ (Table 2). In contrast, BPAF and BPAF-G showed PXR antagonistic activities following stimulation with $10 \mu \mathrm{M}$ rifaximin (PXR agonist). These activities occurred in the low micromolar range for BPAF and BPAF-G (Table 2).

These bisphenols were also tested for their FXR agonistic (Fig. 4C) and antagonistic (Fig. 4D) activities in a transactivation assay using FXR-transfected HepG2 cells. The FXR agonistic activities were initially tested at $10 \mu \mathrm{M}$ bisphenols, as for CDCA as the positive control. Significant increases in luciferase expression were only seen with BPAF. The FXR agonistic activity of BPAF was further confirmed by the dose-response curve, with an $\mathrm{EC}_{50}$ of $5.59 \mu \mathrm{M}$ (Table 2). Moreover, BPAF was the only bisphenol that showed FXR antagonistic activity, with an $\mathrm{IC}_{50}$ of $4.9 \mu \mathrm{M}$ (Table 2).

The PPAR $\gamma$ agonistic and antagonistic activities were then tested for BPA, BPAF and BPAF-G. Here, none of these showed PPAR $\gamma$ agonistic activities (Fig. 4E), while BPA and BPAF-G showed dose-dependent antagonistic activities following $100 \mathrm{nM}$ rosiglitazone (PPAR $\gamma$ agonist), with $\mathrm{IC}_{50}$ of $3.1 \mu \mathrm{M}$ and $1.7 \mu \mathrm{M}$, respectively (Fig. 4F).

\subsection{BPA, BPAF, and BPAF-G effects on lipid accumulation in 3T3L1 preadypocytes}

The effects of BPAF and BPAF-G on adipocyte differentiation were also compared with those of BPA by quantification of lipid accumulation using Nile Red staining. Here, 3T3L1 cells were initially treated with $0.1 \mu \mathrm{M}$ to $10 \mu \mathrm{M}$ BPA for 8 days. This resulted in increased Nile Red lipid staining in comparison with control cells that were treated with DIM alone, which indicated a higher differentiation rate with BPA (Fig. 5). Indeed, the quantification of Nile Red staining indicated significant lipid accumulation even at the lowest tested BPA concentration $(0.1 \mu \mathrm{M})$, which inducing a $>3$-fold increase in fluorescence levels relative to the control. BPAF also significantly increased lipid accumulation at all of the tested 
concentrations $(0.1,1.0,10 \mu \mathrm{M})$, although to a significantly lesser extent than its

362

363

structural analog BPA at the corresponding concentrations. Interestingly, BPAF-G increased lipid accumulation at $1 \mu \mathrm{M}$ and $10 \mu \mathrm{M}$ in a dose-dependent manner, demonstrating a different pattern of effects than seen for both BPA and BPAF, where their effects at $1 \mu \mathrm{M}$ were higher than at $10 \mu \mathrm{M}$ (Fig. 5).

\subsection{BPA, BPAF, and BPAF-G effects on mRNA expression of transcriptional} regulators of adipogenesis and adipogenic markers in 3T3L1 preadypocytes

To further evaluate the extent of adipocyte differentiation, and to compare the effects induced by BPA, BPAF, and BPAF-G on differentiation, quantitative real-time PCR was used to evaluate mRNA expression of four known adipogenic markers: adiponectin, Fabp4, Cebp $\alpha$, and PPAR $\gamma$. These were determined on days 4 and 8 post-treatment, in response to $1 \mu \mathrm{M}$ and $10 \mu \mathrm{M}$ bisphenols, relative to the DIM control.

On day 4 post-treatment, both concentrations of BPA showed statistically significant increases in mRNA levels of the adipogenic marker Fabp4 compared to mRNA levels for DIM, by 2.3-fold and 4.5-fold, respectively (Fig. 6). Of note, $10 \mu \mathrm{M}$ BPAF-G increased Fabp4 expression more than BPA, at 5.5-fold relative to DIM. In addition, $10 \mu \mathrm{M}$ BPA increased the expression of the adipogenic marker adiponectin by 1.6-fold relative to DIM.

After 8 days of differentiation, the bisphenols maintained the high levels of adiponectin, especially with $10 \mu \mathrm{M}$ BPA, at a 2.5-fold increase, and $10 \mu \mathrm{M}$ BPAF-G, at a 2.0fold increase. Instead, $10 \mu \mathrm{M}$ BPAF increased the expression levels of Cebp $\alpha$, as a 2.0-fold increase relative to DIM, which is one of the major adipogenic transcription factors for terminal differentiation. Interestingly, the master regulator of adipogenesis of PPAR $\gamma$ 
expression was not increased relative to DIM through the course of differentiation with these cells treated with BPA, BPAF, and BPAF-G, at both $1 \mu \mathrm{M}$ and $10 \mu \mathrm{M}$. The other master regulator of adipogenesis examined here, Cebp $\alpha$, was increased after 8 days with $1 \mu \mathrm{M}$ and $10 \mu \mathrm{M}$ both BPA and BPAF, relative to the control. For the mature adipocyte marker Fabp4, the mRNA expression levels were significantly increased mostly after 4 days of differentiation for these tested bisphenols, and after 8 days of differentiation at $10 \mu \mathrm{M}$ BPA and BPAF-G.

\section{Discussion}

Recent studies have highlighted the elevated toxicity of BPAF in comparison with other bisphenols, and have thus raise questions about its safety in terms of human health (Mokra et al., 2016; Macczak et al., 2017). The present study thus investigated the influence of glucuronidation of BPAF on some endocrine activities. While the estrogenic agonistic activities of BPAF and BPAF-G are well known, much less is known about their activities on other nuclear receptors, and so this was explored in detail here.

Understanding BPAF metabolism is important for the interpretation of its potential toxicity in humans. It is known that metabolism can enhance endocrine activities of a compound, as already reported for the BPA oxidative metabolite 4-methyl-2,4-bis $(p$ hydroxyphenyl)pent-1-ene, which showed about 500 -fold higher estrogenic activity than BPA (Gramec Skledar and Peterlin Masic, 2016). Conjugation reactions are the most important metabolic transformations for BPAF, and these lead mainly to BPAF-G, and to a lesser extent, to BPAF sulfate (Gramec Skledar and Peterlin Masic, 2016). The incubations of BPAF with HLMs and HIMs here showed that its glucuronidation can start 
in the intestine. However, we confirmed that the liver will be the main place for BPAF glucuronidation, with glucuronidation rates for HLMs about 5-fold those of HIMs.

The next step in the present study was to determine which of a number of UGTs might be responsible for BPAF glucuronidation. Similar screening of UGTs for BPAF glucuronidation was performed by Li and coworkers (Li et al., 2013), and they reported that UGT 2B7 showed the highest BPAF glucuronidation activity. However, here we have extended their study by including five further UGTs that have never been tested for BPAF glucuronidation before: UGTs 1A5, 2A1, 2A2, 2A3, and 2B28. The extrahepatic UGTs 2A1 and 2A2, which are mainly expressed in nasal epithelium and airways, and the intestinal UGT 1A10, showed the highest BPAF glucuronidation rates here. High activities of UGT 2A1 toward different bisphenols was reported previously (Gramec Skledar et al., 2015); however, for BPAF, this might not be so important, as ingestion with food or liquid would appear to be the main intake of BPAF. UGT $1 \mathrm{~A} 10$ is expressed mainly in intestine, and it showed high BPAF glucuronidation rates, and therefore it might be responsible for presystemic metabolism of BPAF. This observation is in contrast with the study of Li and coworkers (Li et al., 2013), where UGT 1A10 showed no activity toward BPAF. However, it has been confirmed several times that the commercially available UGT 1A10 has low activity, and therefore that the glucuronidation rates of UGT $1 \mathrm{~A} 10$ have often been underestimated (Zhu et al., 2012).

The hepatic UGTs 2B7, 2B17, and 1A3 showed moderate BPAF glucuronidation rates, while those of UGTs $2 \mathrm{~B} 15,1 \mathrm{~A} 9$, and $1 \mathrm{~A} 1$ were low. While these screening data might appear to be in contrast with the higher BPAF glucuronidation rates in HLMs than HIMs, there is a logical explanation for this observation: although their BPAF glucuronidation rates are lower than those of the intestinal UGT 1A10, their expression levels in liver are 
very high. Furthermore, as we determined in the kinetics analysis, the hepatic UGT 2B7 and 2B17 showed very high affinities for BPAF, with $\mathrm{K}_{\mathrm{m}}$ in the low micromolar range.

In the second part of the present study, we focused on the endocrine activities of BPAF and BPAF-G, compared to BPA. This is the first study where BPAF and BPAF-G have been comprehensively studied for their effects on several nuclear receptors in vitro and in silico, and again, compared to BPA. Both BPA and BPAF showed ER agonistic activity, as has been reported previously in different in-vitro and in-vivo studies (Table 1), while BPAF-G was without ER activity. Absence of estrogenic activity has already been determined for various bisphenol glucuronides; namely, BPA-G (Matthews et al., 2001), BPS-G (Skledar et al., 2016), and BPAF-G (Li et al., 2013). Our in-silico studies showed that BPAF-G appears too bulky to fit the binding site of ER, thus providing support for the invitro data (see Article in Brief). With the new validated OECD test method 455, BPAF showed 7.5-fold more potent ER agonistic activity compared to BPA, with $\mathrm{EC}_{50}$ of $0.15 \mu \mathrm{M}$ and $1.12 \mu \mathrm{M}$, respectively. The estrogenic potencies of BPAF in the low micromolar range obtained with reporter gene assay on Hela9903 cell line are consistent with estrogenic assays that have been reported in the literature (Table 1). The potential for ER agonistic activities of BPA and BPAF was also shown with the molecular modeling, as they showed similar binding to that of E2.

In addition to the estrogenic activities of bisphenols, which have been the most studied, they can have significant activities toward several other nuclear receptor systems, as also confirmed in the present study. Both, BPA and BPAF showed antagonistic activities toward the androgen and thyroid receptor pathways, although BPAF-G showed no activity here. The comparable androgenic antagonistic potencies of BPA and BPAF seen here is in agreement with previous studies (Kitamura et al., 2005; Fic et al., 2014, Kolšek et al., 2015). Different studies have described antagonist activities of BPA on thyroid 
receptors (Moriyama et al., 2002; Zoeller et al., 2005; Sun et al., 2009); however, there

459

460

461

462

463

464

465

466

467

468 have only been two in-vitro studies that have described thyroid activity for BPAF, and their outcomes are contradictory. BPAF showed no thyroid hormone activity when induction of growth-hormone production was measured in GH3 cells (Kitamura et al., 2005), but showed thyroid hormone receptor agonistic activity using a yeast two-hybrid assay (Lei et al., 2016). Contrary to these data, we show here potent thyroid antagonistic activity of BPAF that was about 10-fold that of BPA. With molecular modeling, we showed that BPA and BPAF, but not BPAF-G, can bind to the T3 binding site. However, in comparison with $\mathrm{T} 3$, they do not offer enough steric and/or binding-interaction complementarity with the binding site for receptor activation, which supports the absence of agonist activity on the thyroid receptor in this in-vitro assay. All three of these bisphenols, BPA, BPAF, and BPAF-G, were without significant glucocorticoid agonistic or antagonistic activities. This is in agreement with Kolšek et al. (2015), who evaluated BPA and BPAF glucocorticoid activities using the same cell line as in the present study (i.e., MDA-kb2 cells). They reported lack activity on glucocorticoid receptors for both BPA and BPAF at $10 \mu \mathrm{M}$ (Kolšek et al., 2015).

Many endocrine-disrupting chemicals, including BPA, have been shown to activate PXR, which is a nuclear receptor that functions as a master regulator of metabolism of xenobiotics, as well as of endogenous molecules (Sui et al., 2012). PXR is a xenobiotic sensor that regulates their clearance via induction of genes involved in drug and xenobiotic metabolism, and it has been implicated in lipid homeostasis, atherosclerosis, and carcinogenesis (Sui et al., 2014). In the present study, BPA showed potent PXR agonistic activity (IC $50,0.65 \mu \mathrm{M}$ ). This is in agreement with Sui et al. (Sui et al., 2012), who reported that BPA is a potent agonist for human PXR, but does not affect mouse PXR activity. Moreover, the binding mode of BPA in the PXR ligand-binding site is similar to 
that reported by Sui et al. (Sui et al., 2012). In the present study, both BPAF and BPAF-G were without agonistic activity toward PXR. In contrast, Sui et al. (2012) reported agonist PXR activity of BPAF at $>5 \mu \mathrm{M}$. However, induction of luciferase activity in that study was 2 fold greater for BPA than BPAF at all three tested concentrations (i.e., $5 \mu \mathrm{M}, 10 \mu \mathrm{M}, 20$ $\mu \mathrm{M}$ ), defining BPAF as a weak PXR agonist in comparison with BPA (Sui et al., 2012). However, in the present study, both BPAF and BPAF-G showed PXR antagonistic activities in the low micromolar range, thus revealing opposite effects on the modulation of PXR activity. Antagonistic PXR activity was also confirmed for BPS, using the HepG2/PXR cell line (Zenata et al., 2017), while BPS was without agonist PXR activity according to two invitro studies (Peyre et al., 2014; Zenata et al., 2017). These studies demonstrate that despite similarities in structure, the same effects on nuclear receptors as observed with BPA cannot be assumed for its structural analogs. Indeed, while BPA is a PXR agonist, its analogs BPS and BPAF act as PXR antagonists.

Sui et al. also reported that BPA was inactive on FXR (Sui et al., 2012), and in the present study, significant agonistic and antagonistic activities toward FXR were only seen for BPAF, with BPA and BPAF-G without FXR activity. Different binding modes of BPA in the ligand-binding site of FXR in the agonist-bound and antagonist-bound conformations were observed by the molecular docking here. In more detail, in the FXR agonist-bound conformation, BPA can form a hydrogen bond with the Thr288 side chain, which can also be observed for the agonist MFA-1 (Soisson et al., 2008). Instead, in the FXR antagonistbound conformation, BPA can interact with the Ala452 and Met456 backbone amides.

It was reported previously that BPA is not a PPAR $\gamma$ agonist, while its halogenated analogs (brominated, chlorinated BPA analogs), and also their sulfates, act as PPAR $\gamma$ agonists (Riu et al., 2011a; Riu et al., 2011b). We confirmed here that none of these bisphenols, BPA, BPAF, and BPAF-G, showed agonistic activities for PPAR $\gamma$. However, BPA 
and BPAF-G showed PPAR $\gamma$ antagonistic activities, with $\mathrm{IC}_{50}$ in the low micromolar range. The antagonistic PPAR $\gamma$ activities of those bisphenols have not been tested before. However, Wright et al (2000) reported that BPA diglycidyl ether can antagonize PPAR $\gamma$ transcriptional activity induced by the PPAR $\gamma$ agonist rosiglitazone (Wright et al., 2000). Taken together, BPAF showed strong agonistic activity toward $\mathrm{hER} \alpha$ and moderate (i.e., low micromolar range) antagonistic activities toward the androgen receptor, thyroid receptor, and PXR. BPAF-G was completely inactive in the reporter assays for $\mathrm{hER} \alpha$, the androgen, thyroid, and glucocorticoid receptors, and FXR, while it showed antagonistic activities toward PXR and PPAR $\gamma$ (in the low micromolar range). This thus indicates that this main metabolite of BPAF, BPAF-G, is not completely inactive, as was proposed in the past. The most potent activities for all three of these tested bisphenols were the hER $\alpha$ agonistic activity of BPAF $\left(\mathrm{EC}_{50}, 150 \mathrm{nM}\right)$ and the PXR agonistic activity of $\mathrm{BPA}\left(\mathrm{EC}_{50}, 650\right.$ $\mathrm{nM}$ ). These justify further studies to evaluate the potential risks for human health.

The present study is the first to report that the BPA analog BPAF, and particularly BPAF-G, can induce murine 3T3L1 cells to differentiate into adipocytes, as shown here by the Nile Red lipid staining of these cells after 8 days of differentiation. These and other data thus suggest that as for BPA, BPA-G (Boucher et al., 2015), and BPS (Ahmed and Atlas, 2016; Boucher et al., 2016), BPAF and its metabolite BPAF-G can increase adipogenesis in murine preadipocytes. Additionally, we showed increased induction of the adipogenic genes adiponectin, Fabp4, and Cebp $\alpha$. In particular, after 4 days of differentiation, BPA and BPAF-G (even more so), significantly increased expression of Fabp4, the levels of which are commonly increased at the end of differentiation. Here, the bisphenols induced high levels of this marker in the early stages of adipocyte differentiation, which were much higher than in cells treated only with DIM. This indicates their effective impact on adipogenesis. Conversely, after 8 days of differentiation, BPA and BPAF-G maintained high 
533 levels of adiponectin, which are usually higher in the early stages of differentiation. 534 Furthermore, BPA and mostly BPAF increased the expression levels of Cebp $\alpha$, one of the major adipogenic transcription factors for terminal differentiation. We can conclude here that BPA, BPAF, and BPAF-G increase and extend adipocyte differentiation by acting on target genes that are essential for the different stages of adipogenesis.

Previously, it was shown that BPS can induce lipid accumulation and differentiation in primary human preadipocytes, and that this effect might be mediated via direct activation of the nuclear receptor PPAR $\gamma$. Also, at the human $a P 2$ promoter, PPAR $\gamma$ activation by BPS is enhanced by activation of the glucocorticoid receptor (Ahmed and Atlas, 2016; Boucher et al., 2016). Furthermore, these studies also showed that BPA, BPA-G, and BPS do not directly activate the glucocorticoid receptor to induce adipogenesis. We show here in the luciferase reporter assays that BPAF and BPAF-G do not activate the glucocorticoid receptor and $\operatorname{PAAR} \gamma$, which is the master regulator of adipocyte differentiation. Additional studies will be needed to determine the mechanism of BPAF-induced and BPAF-G-induced adipogenesis.

\section{Conclusions}

This is the first study where BPAF and BPAF-G have been tested on several nuclear receptors using reporter cell lines, with comparisons of these activities with their analog BPA. We can conclude that BPAF is more potent compared to BPA in several luciferase reporter assays, and so BPAF does not represent a harmless substitute for BPA. Metabolism of BPAF to BPAF-G eliminates agonistic estrogen and antagonistic androgen and thyroid activities of BPAF. Nevertheless, BPAF-G shows PXR and PPAR $\gamma$ antagonistic activities in the low micromolar range. We have shown for the first time that 
558 glucuronidation of BPAF results in formation of biologically active metabolites. 559 Additionally, BPAF-G has significant effects on lipid accumulation and differentiation in 560 murine preadipocytes at $1.0 \mu \mathrm{M}$ and higher. Thus, in the future, more thorough 561 toxicological and epidemiological investigations of the BPAF effects on human health are 562 warranted, to provide a better understanding of the metabolic end-elimination fate of 563 BPAF in the human body.

564

565

566 Acknowledgements

567 The authors thank OpenEye Scientific Software, Santa Fe, NM, USA, for free academic 568 licenses for the use of their software, and Johanna Mosorin for skillful assistance in 569 recombinant UGT preparations. Financial support of the Slovenian Research Agency 570 (Grant No. P1-0208) and the Sigrid Juselius Foundation, Finland (grant no. 4704583) are 571 acknowledged. 


\section{References}

Ahmed, S., Atlas, E., 2016. Bisphenol S- and bisphenol A-induced adipogenesis of murine preadipocytes occurs through direct peroxisome proliferator-activated receptor $\gamma$ activation. Int. J. Obes. 40, 1566-1573.

Boucher, J.G., Ahmed, S., Atlas, E., 2016. Bisphenol S induces adipogenesis in primary human preadipocytes from female donors. Endocrinology 157, 1397-1407.

Boucher, J.G., Boudreau, A., Ahmed, S., Atlas, E., 2015. In-vitro effects of bisphenol A $\beta$-Dglucuronide (BPA-G) on adipogenesis in human and murine preadipocytes. Environ. Health Perspect. 123, 1287-1293.

Cesen, M., Lambropoulou, D., Laimou-Geraniou, M., Kosjek, T., Blaznik, U., Heath, D., Heath, E., 2016. Determination of bisphenols and related compounds in honey and their migration from selected food contact materials. J. Agric. Food Chem. 64, 8866-8875.

Feng, Y., Jiao, Z., Shi, J., Li, M., Guo, Q., Shao, B., 2016. Effects of bisphenol analogues on steroidogenic gene expression and hormone synthesis in H295R cells. Chemosphere 147, 9-19.

Fic, A., Zegura, B., Gramec, D., Mašič, L.P., 2014. Estrogenic and androgenic activities of TBBA and TBMEPH, metabolites of novel brominated flame retardants, and selected bisphenols, using the XenoScreen XL YES/YAS assay. Chemosphere 112, 362-369.

Gramec Skledar, D., Peterlin Masic, L., 2016. Bisphenol A and its analogs: do their metabolites have endocrine activity? Environ. Toxicol. Pharmacol. 47, 182-199.

Gramec Skledar, D., Troberg, J., Lavdas, J., Peterlin Mašič, L., Finel, M., 2015. Differences in the glucuronidation of bisphenols $\mathrm{F}$ and $\mathrm{S}$ between two homologous human UGT enzymes, 1A9 and 1A10. Xenobiotica 45, 511-519.

Karrer, C., Roiss, T., von Goetz, N., Gramec Skledar, D., Peterlin Mašič, L., Hungerbühler, K., 2018. Physiologically based pharmacokinetic (PBPK) modeling of the bisphenols 
BPA, BPS, BPF, and BPAF with new experimental metabolic parameters: Comparing the pharmacokinetic behavior of BPA with its substitutes. Environ Health Perspect 126:077002.

Kitamura, S., Suzuki, T., Sanoh, S., Kohta, R., Jinno, N., Sugihara, K., Yoshihara, S., Fujimoto, N., Watanabe, H., Ohta, S., 2005. Comparative study of the endocrine-disrupting activity of bisphenol A and 19 related compounds. Toxicol. Sci. 84, 249-259.

Kolšek, K., Gobec, M., Mlinarič Raščan, I., Sollner Dolenc, M., 2015. Screening of bisphenol A, triclosan and paraben analogues as modulators of the glucocorticoid and androgen receptor activities. Toxicol. In Vitro 29, 8-15.

Lei, B., Xu, J., Peng, W., Wen, Y., Zeng, X., Yu, Z., Wang, Y., Chen, T., 2016. In-vitro profiling of toxicity and endocrine disrupting effects of bisphenol analogues by employing MCF-7 cells and two-hybrid yeast bioassay. Environ. Toxicol. 32, 278-289.

Li, M., Yang, Y.J., Yang, Y., Yin, J., Zhang, J., Feng, Y.X., Shao, B., 2013. Biotransformation of bisphenol AF to its major glucuronide metabolite reduces estrogenic activity. PLoS One 8, e83170.

Liang, S., Yin, L., Shengyang Yu, K., Hofmann, M.C., Yu, X., 2017. High-content analysis provides mechanistic insights into the testicular toxicity of bisphenol A and selected analogues in mouse spermatogonial cells. Toxicol. Sci. 155, 43-60.

Liao, C., Kannan, K., 2013. A survey of bisphenol A and other bisphenol analogues in foodstuffs from nine cities in China. Food Addit. Contam. Part A Chem. Anal. Control Expo. Risk Assess. 31, 319-329.

Liao, C., Liu, F., Guo, Y., Moon, H.B., Nakata, H., Wu, Q., Kannan, K., 2012. Occurrence of eight bisphenol analogues in indoor dust from the United States and several Asian countries: implications for human exposure. Environ. Sci. Technol. 46, 9138-9145. 
Macczak, A., Cyrkler, M., Bukowska, B., Michalowicz, J., 2017. Bisphenol A, bisphenol S, bisphenol $\mathrm{F}$ and bisphenol AF induce different oxidative stress and damage in human red blood cells (in-vitro study). Toxicol. In Vitro 41, 143-149.

Matthews, J.B., Twomey, K., Zacharewski, T.R., 2001. In-vitro and in-vivo interactions of bisphenol A and its metabolite, bisphenol A glucuronide, with estrogen receptors alpha and beta. Chem. Res. Toxicol. 14, 149-157.

Mokra, K., Kuzminska-Surowaniec, A., Wozniak, K., Michalowicz, J., 2016. Evaluation of DNA-damaging potential of bisphenol A and its selected analogs in human peripheral blood mononuclear cells (in-vitro study). Food Chem. Toxicol. 100, 62-69.

Moriyama, K., Tagami, T., Akamizu, T., Usui, T., Saijo, M., Kanamoto, N., Hataya, Y., Shimatsu, A., Kuzuya, H., Nakao, K., 2002. Thyroid hormone action is disrupted by bisphenol A as an antagonist. J. Clin. Endocrinol. Metab. 87, 5185-5190.

Peyre, L., Rouimi, P., de Sousa, G., Héliès-Toussaint, C., Carré, B., Barcellini, S., Chagnon, M.C., Rahmani, R., 2014. Comparative study of bisphenol A and its analogue bisphenol S on human hepatic cells: a focus on their potential involvement in nonalcoholic fatty liver disease. Food Chem. Toxicol. 70, 9-18.

Prasanth, G.K., Divya, L.M., Sadasivan, C., 2010. Bisphenol-A can bind to human glucocorticoid receptor as an agonist: an in-silico study. J. Appl. Toxicol. 30, 769-774.

Regueiro, J., Wenzl, T., 2015a. Determination of bisphenols in beverages by mixed-mode solid-phase extraction and liquid chromatography coupled to tandem mass spectrometry. J. Chromatogr. A 1422, 230-238.

Regueiro, J., Wenzl, T., 2015b. Development and validation of a stable-isotope dilution liquid chromatography-tandem mass spectrometry method for the determination of bisphenols in ready-made meals. J. Chromatogr. A 1414, 110-121. 
Riu, A., Grimaldi, M., le Maire, A., Bey, G., Phillips, K., Boulahtouf, A., Perdu, E., Zalko, D., Bourguet, W., Balaguer, P., 2011a. Peroxisome proliferator-activated receptor $\gamma$ is a target for halogenated analogs of bisphenol A. Environ. Health Perspect. 119, 12271232.

Riu, A., le Maire, A., Grimaldi, M., Audebert, M., Hillenweck, A., Bourguet, W., Balaguer, P., Zalko, D., 2011b. Characterization of novel ligands of ER $\alpha, E R \beta$, and PPAR $\gamma$ : the case of halogenated bisphenol A and their conjugated metabolites. Toxicol. Sci. 122, 372382.

Ruan, T., Liang, D., Song, S., Song, M., Wang, H., Jiang, G., 2015. Evaluation of the in-vitro estrogenicity of emerging bisphenol analogs and their respective estrogenic contributions in municipal sewage sludge in China. Chemosphere 124, 150-155.

Sato, Y., Nagata, M., Tetsuka, K., Tamura, K., Miyashita, A., Kawamura, A., Usui, T., 2014. Optimized methods for targeted peptide-based quantification of human uridine 5'diphosphate-glucuronosyltransferases in biological specimens using liquid chromatography-tandem mass spectrometry. Drug Metab. Dispos. 42, 885-889.

Skledar, D.G., Schmidt, J., Fic, A., Klopcic, I., Trontelj, J., Dolenc, M.S., Finel, M., Masic, L.P., 2016. Influence of metabolism on endocrine activities of bisphenol S. Chemosphere $157,152-159$.

Soisson, S.M., Parthasarathy, G., Adams, A.D., Sahoo, S., Sitlani, A., Sparrow, C., Cui, J., Becker, J.W., 2008. Identification of a potent synthetic FXR agonist with an unexpected mode of binding and activation. Proc. Natl. Acad. Sci. USA 105, 5337-5342.

Song, M., Liang, D., Liang, Y., Chen, M., Wang, F., Wang, H., Jiang, G., 2014. Assessing developmental toxicity and estrogenic activity of halogenated bisphenol A on zebrafish (Danio rerio). Chemosphere 112, 275-281. 
Song, S., Ruan, T., Wang, T., Liu, R., Jiang, G., 2012. Distribution and preliminary exposure assessment of bisphenol AF (BPAF) in various environmental matrices around a manufacturing plant in China. Environ. Sci. Technol. 46, 13136-13143.

Sui, Y., Ai, N., Park, S.-H., Rios-Pilier, J., Perkins, J.T., Welsh, W.J., Zhou, C., 2012. Bisphenol A and its analogues activate human pregnane X receptor. Environ. Health Perspect. $120,399-405$.

Sui, Y., Park, S.-H., Helsley, R.N., Sunkara, M., Gonzalez, F.J., Morris, A.J., Zhou, C., 2014. Bisphenol A increases atherosclerosis in pregnane $\mathrm{X}$ receptor-humanized ApoE deficient mice. J. Am. Heart Assoc. 3: e000492.

Sun, H., Shen, O.X., Wang, X.R., Zhou, L., Zhen, S.Q., Chen, X.D., 2009. Anti-thyroid hormone activity of bisphenol $\mathrm{A}$, tetrabromobisphenol $\mathrm{A}$ and tetrachlorobisphenol $\mathrm{A}$ in an improved reporter gene assay. Toxicol. In Vitro 23, 950-954.

Tang, T., Yang, Y., Chen, Y., Tang, W., Wang, F., Diao, X., 2015. Thyroid disruption in zebrafish larvae by short-term exposure to bisphenol AF. Int. J. Environ. Res. Public Health 12, 13069-13084.

Teng, C., Goodwin, B., Shockley, K., Xia, M., Huang, R., Norris, J., Merrick, B.A., Jetten, A.M., Austin, C.P., Tice, R.R., 2013. Bisphenol A affects androgen receptor function via multiple mechanisms. Chem.-Biol. Inter. 203, 556-564.

Tisler, T., Krel, A., Gerzelj, U., Erjavec, B., Dolenc, M.S., Pintar, A., 2016. Hazard identification and risk characterization of bisphenols $\mathrm{A}, \mathrm{F}$ and $\mathrm{AF}$ to aquatic organisms. Environ. Poll. 212, 472-479.

Waidyanatha, S., Mathews, J.M., Patel, P.R., Black, S.R., Snyder, R.W., Fennell, T.R., 2015. Disposition of bisphenol AF, a bisphenol A analogue, in hepatocytes in vitro and in male and female Harlan Sprague-Dawley rats and B6C3F1/N mice following oral and intravenous administration. Xenobiotica 45, 811-819. 
Wright, H.M., Clish, C.B., Mikami, T., Hauser, S., Yanagi, K., Hiramatsu, R., Serhan, C.N., Spiegelman, B.M., 2000. A synthetic antagonist for the peroxisome proliferatoractivated receptor gamma inhibits adipocyte differentiation. J. Biol. Chem. 275, 18731877.

Yu, X., Xue, J., Yao, H., Wu, Q., Venkatesan, A.K., Halden, R.U., Kannan, K., 2015. Occurrence and estrogenic potency of eight bisphenol analogs in sewage sludge from the US EPA targeted national sewage sludge survey. J. Hazard Mater. 299, 733-739.

Zenata, O., Dvorak, Z., Vrzal, R., 2017. Profiling of bisphenol S towards nuclear receptors activities in human reporter cell lines. Toxicol. Lett. 281, 10-19.

Zhu, L., Ge, G., Zhang, H., Liu, H., He, G., Liang, S., Zhang, Y., Fang, Z., Dong, P., Finel, M., Yang, L., 2012. Characterization of hepatic and intestinal glucuronidation of magnolol: application of the relative activity factor approach to decipher the contributions of multiple UDP-glucuronosyltransferase isoforms. Drug Metab. Dispos. 40, 529-538.

Zoeller, R.T., Bansal, R., Parris, C., 2005. Bisphenol-A, an environmental contaminant that acts as a thyroid hormone receptor antagonist in vitro, increases serum thyroxine, and alters RC3/neurogranin expression in the developing rat brain. Endocrinology $146,607-612$. 
Table 1: In-vitro activities of BPAF toward nuclear receptors.

\begin{tabular}{|c|c|c|c|c|}
\hline \multirow[t]{2}{*}{ Assay } & \multicolumn{2}{|c|}{$\begin{array}{c}\mathrm{EC}_{50} / \mathrm{IC}_{50} \\
(\mu \mathrm{M})\end{array}$} & \multirow{2}{*}{$\begin{array}{c}\text { Relative } \\
\text { potency } \\
\text { (BPAF/BPA) }\end{array}$} & \multirow[t]{2}{*}{ Reference } \\
\hline & BPAF & BPA & & \\
\hline \multicolumn{5}{|l|}{ Estrogen agonist activity } \\
\hline YES assay & 0.39 & 3.60 & 9.2 & (Fic et al., 2014) \\
\hline Yeast 2-hybrid & 5.3 & 34.1 & 6.4 & (Lei et al., 2016) \\
\hline BLYES assay & 0.61 & 4.1 & 6.7 & (Ruan et al., 2015) \\
\hline MCF7 luc & 0.05 & 0.63 & 12.6 & (Kitamura et al., 2005) \\
\hline CV1 monkey kidney cells & 0.097 & 0.27 & 2.8 & (Teng et al., 2013) \\
\hline
\end{tabular}

\section{Androgen antagonist activity}

$\begin{array}{lcccc}\text { NIH353 } & 1.3 & 4.3 & 3.3 & \text { (Kitamura et al., 2005) } \\ \text { YAS assay } & 2.29 & 3.35 & 1.5 & \text { (Fic et al., 2014) } \\ \text { CV1 monkey kidney cells } & 1.29 & 2.34 & 1.8 & \text { (Teng et al., 2013) }\end{array}$

\section{Thyroid agonist activity}

Yeast two-hybrid

$1.4 \quad 30.1$

21.5

(Lei et al., 2016)

Growth hormone production

NA NA

(Kitamura et al., 2005)

\section{hPXR agonist activity}

HepG2 cells co-transfected with

/ (Sui et al., 2012)

hPXR, CYP3A4-luc reporter, and

CMX- $\beta$-galactosidase plasmid

BLYES, bioluminescence yeast estrogen screen; NA, not active; YAS, yeast androgen screen; YES, yeast estrogen screen. *BPAF was a relatively weak PXR agonist compared

717 with BPA; ${ }^{* *}$ The half-maximal effective concentration $\left(\mathrm{EC}_{50}\right)$ for BPA activation of hPXRmediated cytochrome P450 3A4 (CYP3A4) promoter activity was $\sim 9 \mu \mathrm{M}$. 
719 Table 2: Effects of BPA, BPAF and BPAF-G on estrogen, androgen, thyroid, and 720 glucocorticoid receptor activities, and on PXR, FXR, and PPAR $\gamma$ activities.

\begin{tabular}{|c|c|c|c|c|c|}
\hline $\begin{array}{l}\text { Receptor } \\
\text { pathway }\end{array}$ & $\begin{array}{l}\text { Reporter } \\
\text { cell line }\end{array}$ & Activity & Bisphenol & $\begin{array}{c}\mathrm{EC}_{50} / \mathrm{IC}_{50} \\
(\mu \mathrm{M})\end{array}$ & $\begin{array}{c}\text { 95\% confidence } \\
\text { interval }(\mu \mathrm{M})\end{array}$ \\
\hline \multirow[t]{6}{*}{ Estrogen } & Hela9903 & Agonistic & BPA & 1.1 & $0.87-1.44$ \\
\hline & & & BPAF & 0.15 & $0.10-0.22$ \\
\hline & & & BPAF-G & NA & \\
\hline & & Antagonistic & BPA & NA & \\
\hline & & & BPAF & NA & \\
\hline & & & BPAF-G & NA & \\
\hline \multirow[t]{6}{*}{ Androgen } & MDA-kb2 & Agonistic & BPA & NA & \\
\hline & & & BPAF & NA & \\
\hline & & & BPAF-G & NA & \\
\hline & & Antagonistic & BPA & 5.5 & $0.63-1.51$ \\
\hline & & & BPAF & 2.9 & $0.41-1.13$ \\
\hline & & & BPAF-G & NA & \\
\hline \multirow[t]{6}{*}{ Thyroid } & GH3.TRE-luc & Agonistic & BPA & NA & \\
\hline & & & BPAF & NA & \\
\hline & & & BPAF-G & NA & \\
\hline & & Antagonistic & BPA & 88 & $29.2-266.6$ \\
\hline & & & BPAF & 7.6 & $5.94-9.80$ \\
\hline & & & BPAF-G & NA & \\
\hline \multirow[t]{2}{*}{ Glucocorticoid } & MDA-kb2 & Agonistic & BPA & NA & \\
\hline & & & BPAF & NA & \\
\hline
\end{tabular}




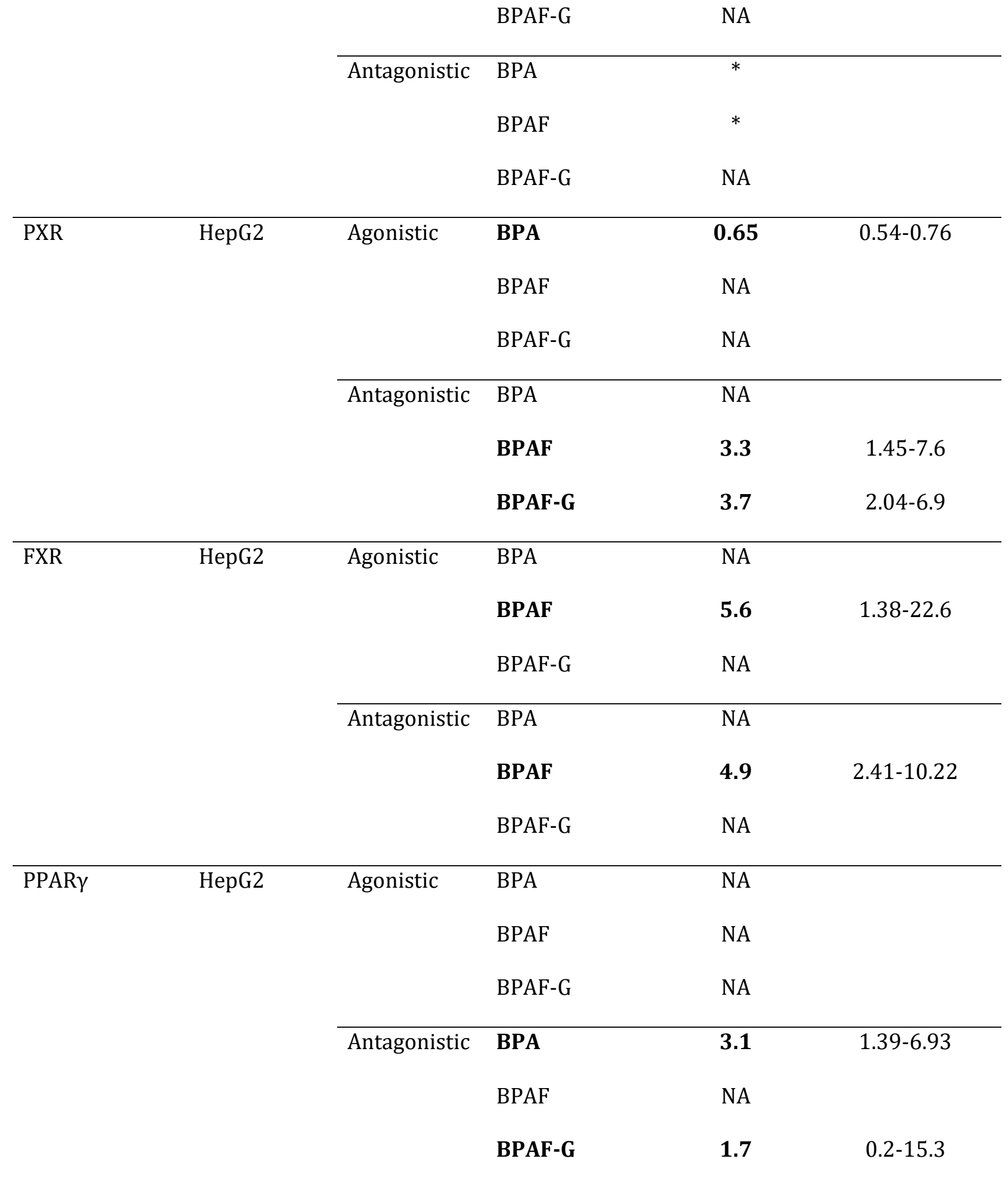

721 NA, not active; *Antagonistic activity on the glucocorticoid receptor pathway was

722 determined at the highest concentrations tested. Due to solubility problems at higher 
723 concentrations, concentration-response curves were not constructed, and $\mathrm{IC}_{50}$ was not 724 determined.

725 
Figure 1. Structures of BPA and BPAF, and the main BPAF metabolite, BPAF-glucuronide.

Figure 2. BPAF glucuronidation rates for individual UGTs, and human liver (HLM) and intestinal (HIM) microsomes, in the presence of $20 \mu \mathrm{M}$ and $50 \mu \mathrm{M}$ BPAF as substrate. (A) BPAF glucuronidation rates for the 17 human recombinant UGTs, including some that are not commercially available. (B) Corrected expression levels for the UGTs in (A) that showed activities. UGT2B15 was not included, as its expression level could not be determined (see Materials). (C) BPAF glucuronidation rates in human liver and intestine microsomes. Data are means \pm S.E. of three independent assays.

Figure 3. Analyses of the agonistic and antagonistic activities of BPA, BPAF, and BPAF-G toward the estrogen, thyroid hormone, androgen, and glucocorticoid receptors. (A, B) ER agonistic (A) and antagonistic (B) activities, with the relevant controls (agonist, E2; antagonist, tamoxifen). (C, D) Thyroid hormone receptor agonistic (C) and antagonistic (D) activities, with the T3 agonist control. (E, F) Androgen agonistic (E) and antagonistic

(F) activities, with the relevant controls (agonist, dihydrotestosterone; antagonist, flutamide). (G, H) Glucocorticoid receptor agonistic (G) and antagonistic (H) activities, with the relevant controls (agonist, hydrocortisone; antagonist, mifepristone). Data are means \pm SE of three independent experiments. See Methods for assay systems used.

Figure 4. Analyses of the agonistic and antagonistic activities of BPA, BPAF, and BPAF-G toward PXR, FXR, and PPAR $\gamma$. (A, B) PXR agonistic (A) and antagonistic (B) activities, with the relevant agonist control (rifaximim). (C, D) FXR agonistic (C) and antagonistic (D) 
activities, with the relevant agonist control (CDCA). (E, F) PPAR $\gamma$ agonistic (E) and

752

antagonistic (F) activities, with the relevant agonist control (rosiglitazon). Data are means \pm SE of three independent experiments. See Methods for assay systems used.

Figure 5. BPA, BPAF, and BPAF-G effects on lipid accumulation in 3T3L1 preadypocytes, as revealed by Nile Red staining and quantification. 3T3L1 preadipocytes were differentiated for 8 days in DIM alone, or in combination with BPA, BPAF, or BPAF-G (0.1, 1.0, $10 \mu \mathrm{M}$ ). (A) Representative staining for lipid accumulation on day 8 of differentiation, with Alexafluor488-conjugated phalloidin and Nile Red (see Methods). (B) Quantification of fluorescence shown in (A). Data are means \pm SE from two experiments, each carried out in triplicate. ${ }^{*} p<0.05$ versus cells treated with DIM alone (arbitrarily set to 100 ).

Figure 6. BPA, BPAF, and BPAF-G effects on differentiation-related gene expression. Preadipocyte 3T3L1 cells were differentiated for 4 or 8 days in the presence of DIM alone (control) or DIM with $1 \mu \mathrm{M}$ or $10 \mu \mathrm{M}$ BPA, BPAF, or BPAF-G. Quantification of relative mRNA expression of adipogenic marker genes: adiponectin, Fabp4, Cebp $\alpha$, and PPAR $\gamma$. Data are means \pm SE from two experiments, each carried out in triplicate. ${ }^{*} p<0.05$ versus differentiated cells (arbitrarily set to 1). Data are normalized to glyceraldehyde-3phosphate dehydrogenase mRNA expression, and expressed as $2^{(-\Delta \Delta C t)}$. 
771

772<smiles>CC(C)(c1ccc(O)cc1)c1ccc(O)cc1</smiles><smiles>Oc1ccc(C(c2ccc(O)cc2)(C(F)(F)F)C(F)(F)F)cc1</smiles><smiles>CC(c1ccc(O)cc1)(c1ccc(OC2OC(C(=O)O)[C@H](O)C(O)C2O)cc1)C(F)(F)F</smiles>

773

$774 \quad$ Figure 1

775 
A.

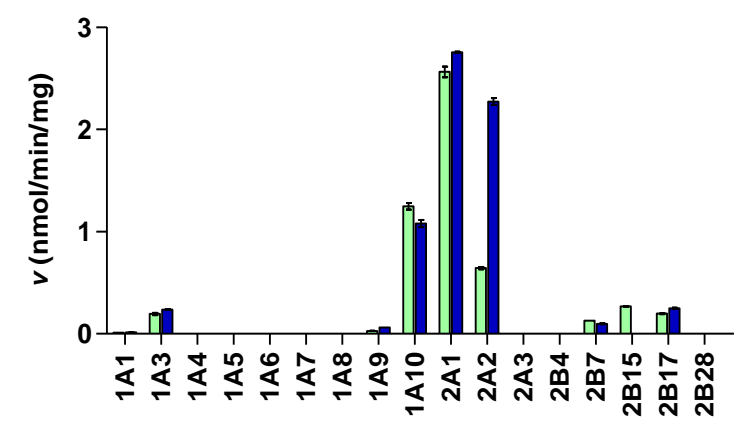

777

778

$779 \quad$ Figure 2

780
B.

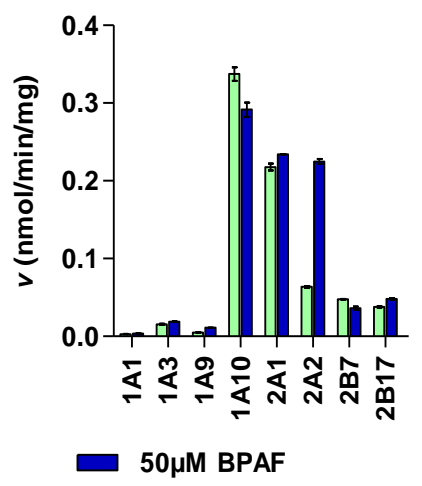

C.

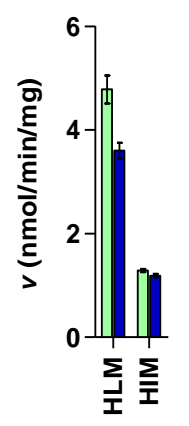


A.

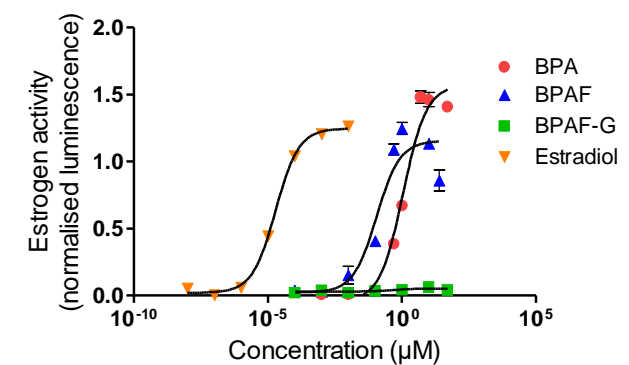

c.

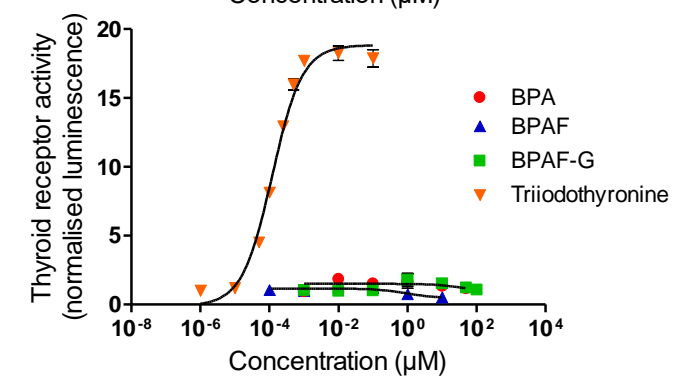

E.

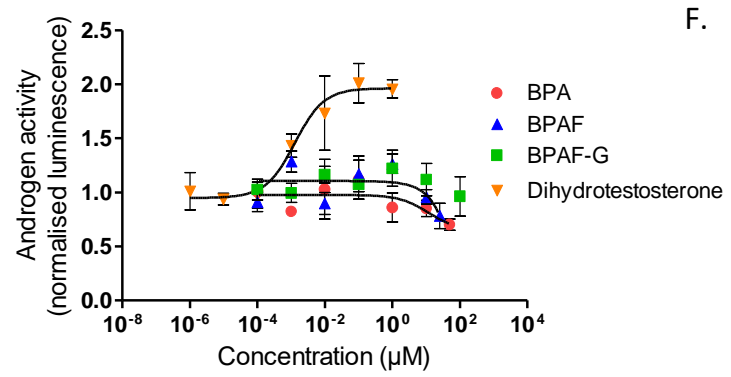

G.

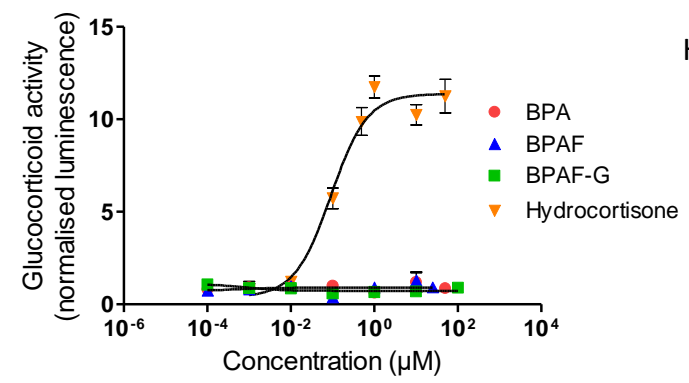

B.

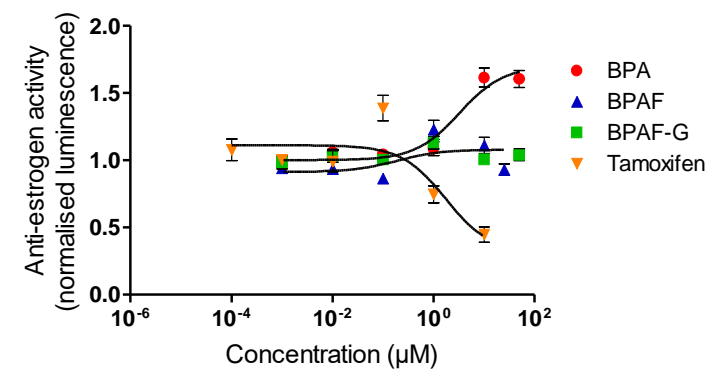

D.

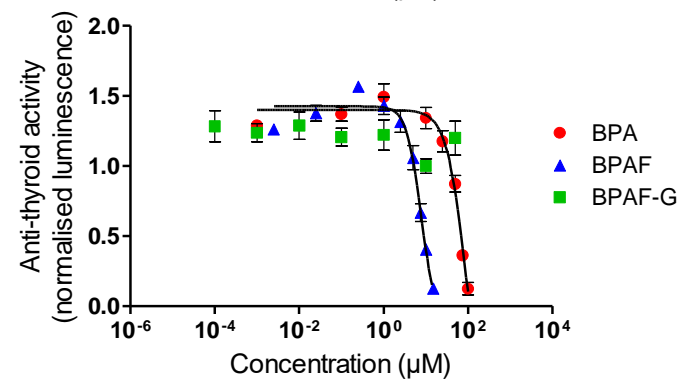

F.

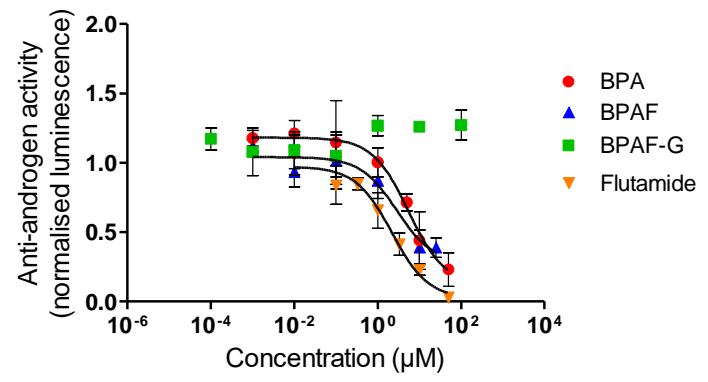

$\mathrm{H}$.

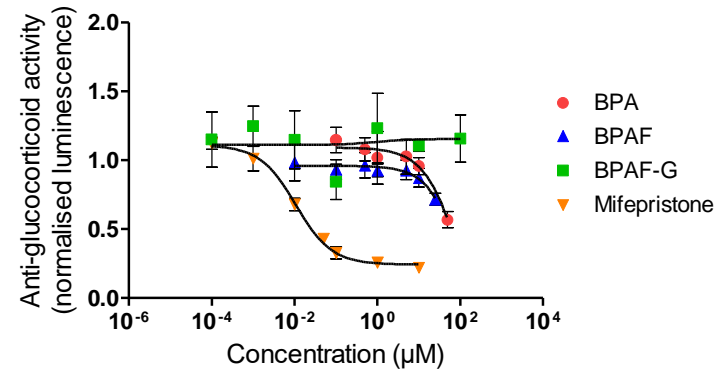


A.

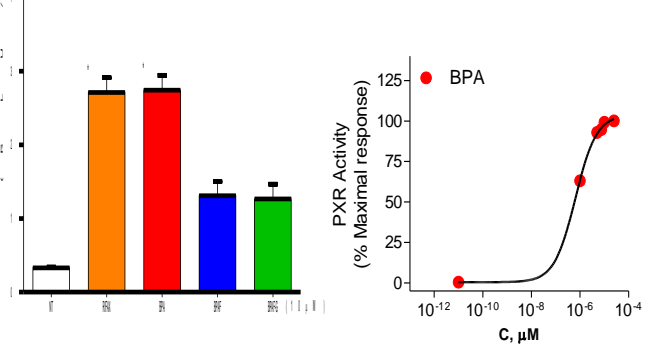

c.

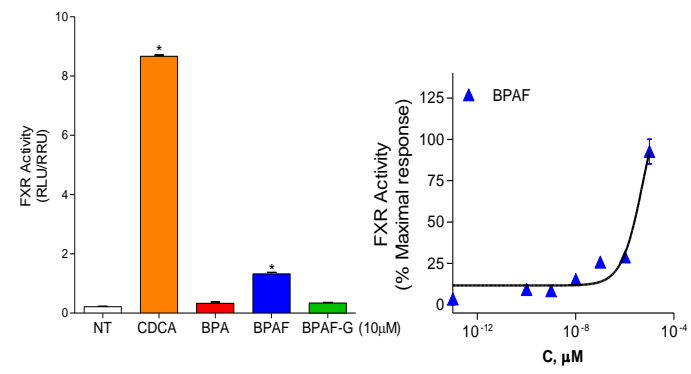

E.

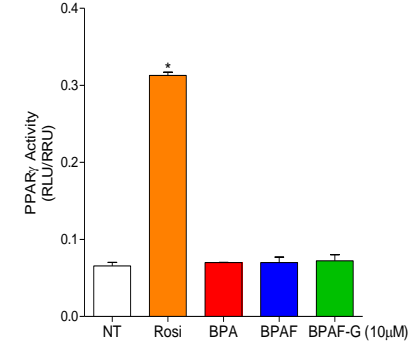

B.

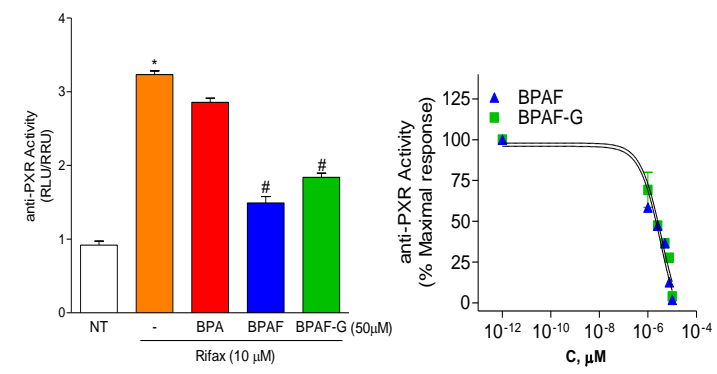

D.
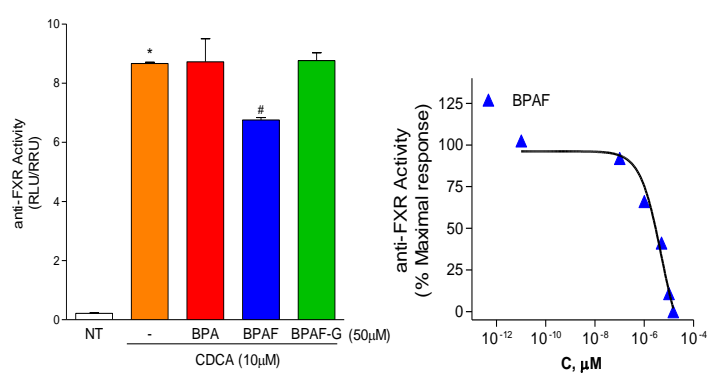

F.

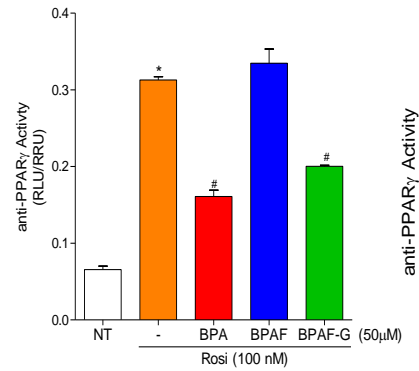

Figure 4 


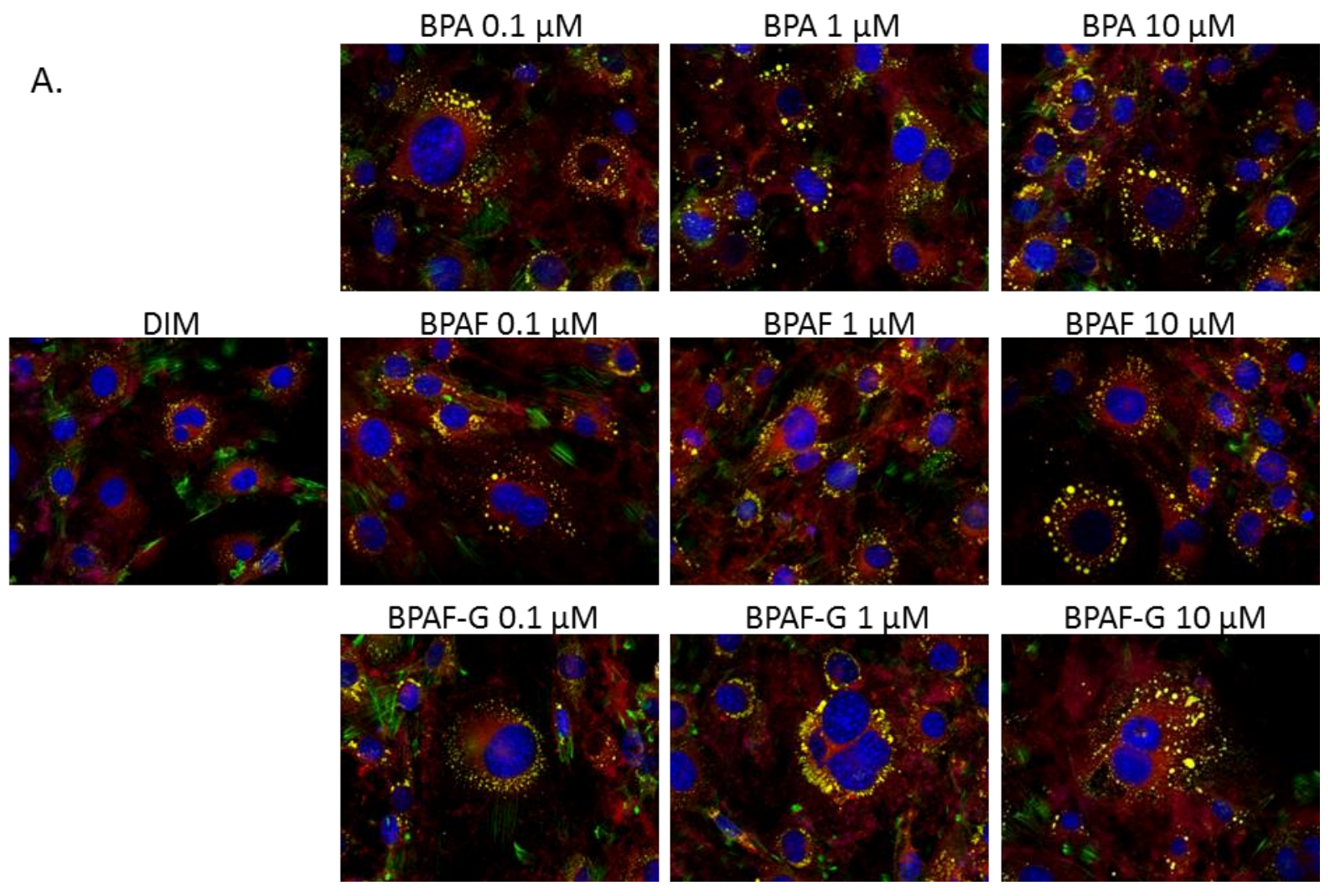

B. Nile Red signal quantification

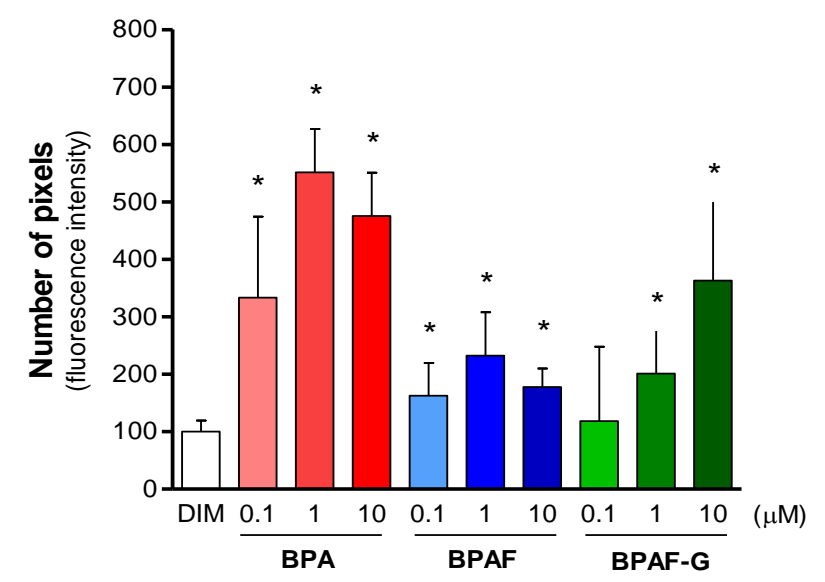

791

792

Figure 5 

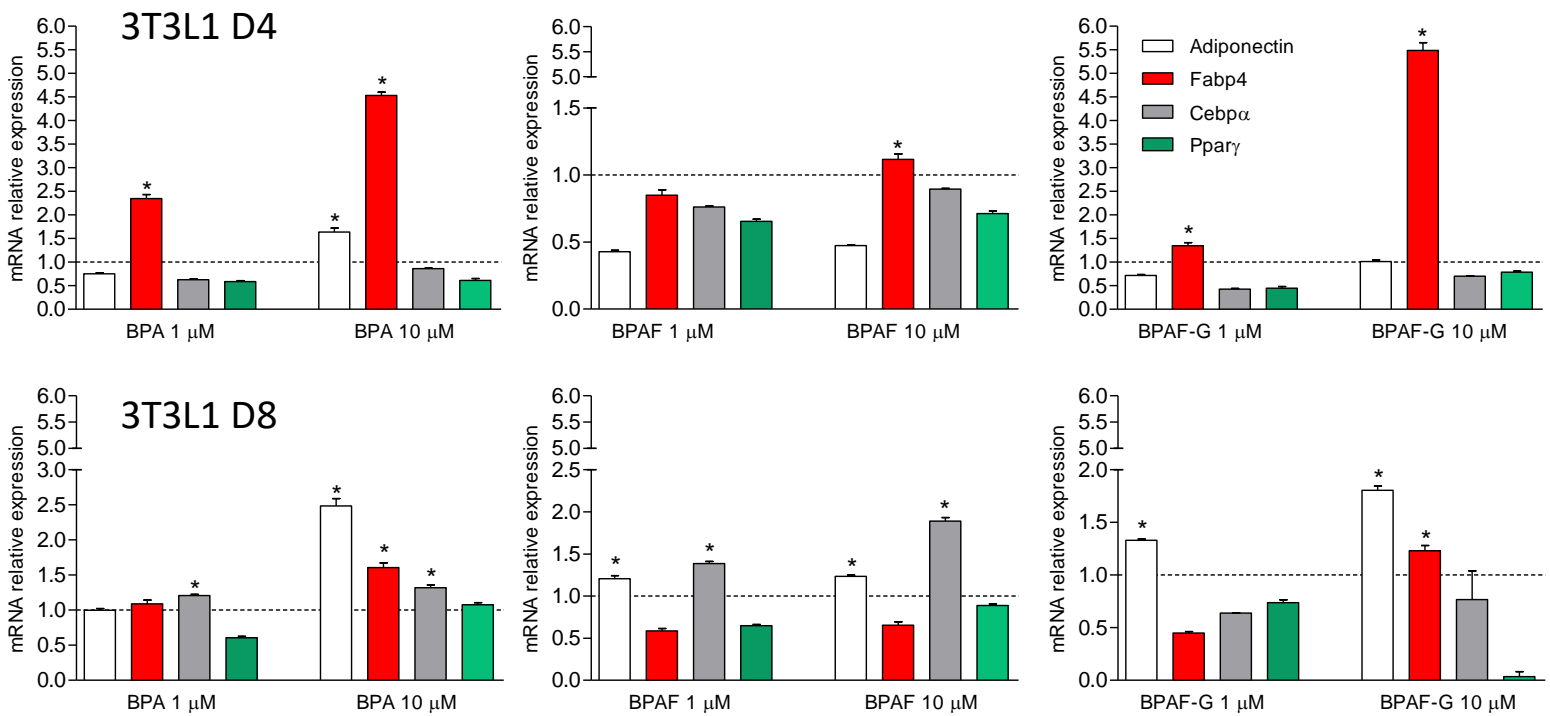

797

798

Figure 6

799

800 